05

\title{
Влияние локального химического состава границ зерен на коррозионную стойкость титанового сплава
}

\author{
(C) В.Н. Чувильдеев ${ }^{1}$, В.И. Копылов ${ }^{1,2}$, А.В. Нохрин ${ }^{1, ~}$ \\ А.М. Бахметьев ${ }^{3}$, Н.Г. Сандлер ${ }^{3}$, П.В. Тряев ${ }^{3}$, \\ Н.А. Козлова ${ }^{1}$, Н.Ю. Табачкова ${ }^{4}$, А.С. Михайлов ${ }^{3}$, \\ М.К. Чегуров ${ }^{1}$, Е.С. Смирнова ${ }^{1}$

\footnotetext{
${ }^{1}$ Национальный исследовательский Нижегородский государственный университет им. Н.И. Лобачевского, Нижний Новгород, Россия

${ }^{2}$ Физико-технический институт НАН Беларуси, Минск, Беларусь

${ }^{3}$ ОКБМ Африкантов, Нижний Новгород, Россия

${ }^{4}$ НИТУ „МИСиС“, Москва, Россия

『E-mail: Nokhrin@nifti.unn.ru
}

Поступило в Редакцию 12 мая 2016 г.

Проведены исследования влияния структурно-фазового состояния границ зерен псевдо- $\alpha$-титанового сплава $\mathrm{Ti}-4 \mathrm{Al}-2 \mathrm{~V}$ (промышленное обозначение ПТЗВ) на склонность к горячей солевой межкристаллитной коррозии (МКК). Показано, что после испытаний на МКК в сплаве наблюдаются два типа коррозионных дефектов. Более протяженные дефекты МКК первого типа располагаются по границам крупных зерен, обогащенных ванадием, а короткие дефекты второго типа - по границам зерен, имеющих химический состав, мало отличающийся от состава тела зерна. Наличие двух типов дефектов МКК объясняется классической теорией возникновения микрогальванических пар, в соответствии с которой интенсивность МКК пропорциональна разности концентраций коррозионно-опасных примесей между границей и телом зерна.

В настоящее время титановые псевдо-альфа-сплавы системы $\mathrm{Ti}-\mathrm{Al}-\mathrm{V}$ широко используются в атомном машиностроении и ядерной энергетике [1-3]. В частности, сплавы $\mathrm{Ti}-\mathrm{Al}-\mathrm{V}$ широко используются для изготовления теплообменного оборудования современных ядерноэнергетических установок (ЯЭУ). Вследствие этого к титановым сплавам предъявляются повышенные требования по коррозионной стойкости, которые определяют работоспособность и эксплуатационную надежность теплообменного оборудования ЯЭУ [3]. 
Опасным видом коррозионного разрушения титановых сплавов является межкристаллитная коррозия (МКК), механизмы которой остаются малоизученными [4]. Особый интерес вызывает изучение влияния роли размера зерна и структурно-фазового состояния границ зерен титановых сплавов на их склонность к МКК [4]. Отметим, что зависимость скорости коррозии от размера зерна в титане и титановых сплавах имеет сложный и неоднозначный характер - для одного и того же материала описано как повышение, так и уменьшение коррозионной стойкости при измельчении зеренной структуры. Например, в работах $[5,6]$ было обнаружено снижение коррозионной стойкости мелкозернистого титана; в [7-10] было показано, что формирование мелкозернистой структуры позволяет повысить коррозионную стойкость титана; в работах [11-13] однозначную связь установить не удалось. Причины этой неоднозначности обусловлены, на наш взгляд, тем, что на развитие МКК в титановых сплавах влияет не только размер зерна, но и локальный химический состав границ зерен.

Целью настоящей работы является исследование влияния локального химического состава границ зерен на склонность сплава $\mathrm{Ti}-\mathrm{Al}-\mathrm{V}$ к горячей солевой МКК.

В качестве объекта исследования выступал промышленный псевдоальфа-титановый деформируемый сплав ПТЗВ состава Тi $-4.73 \mathrm{wt} \%$ $\mathrm{Al}-1.88 \mathrm{wt} \% \mathrm{~V}$. Концентрация кислорода, азота, водорода и углерода составляла $0.039-0.042,0.01,0.0024$ и 0.04 wt \%, соответственно. Химический состав сплава соответствует требованиям ОСТ 192062-90.

Исследования структуры проводились с использованием растрового электронного микроскопа Jeol JSM-6490 с энергодисперсионным микроанализатором INCA 350 и просвечивающего электронного микроскопа Jeol JEM-2100 с энергодисперсионным микроанализатором JED-2300. Рентгенофазовый анализ проводили с использованием автоматизированного дифрактометра Oxford Diffraction GEMINIS.

Коррозионные автоклавные испытания проводились в смеси солей $\mathrm{NaCl}$ и $\mathrm{KBr}$, взятых в соотношении $300: 1$, в среде атмосферного воздуха при температуре $523 \mathrm{~K}$. Испытывались образцы сечением $10 \times 10 \mathrm{~mm}$ и высотой $5 \mathrm{~mm}$. Продолжительность испытаний составляла $500 \mathrm{~h}$. Степень коррозионного повреждения оценивалась в соответствии с требованиями ГОСТ 9.908-85 по глубине прокорродировавшего слоя на боковой поверхности образцов с помощью металлографического микроскопа Leica DM IRM при увеличении $\times 200$.

Письма в ЖТФ, 2016, том 42, вып. 24 
Продукты коррозии (солевые отложения) с поверхности образцов удалялись механически. Глубина прокорродировавшего слоя оценивалась по формуле $L_{c o r}=\left(h_{0}-h_{c o r}\right) / 2+b$, где $h_{0}$ - начальная высота образца (до испытаний), $h_{c o r}$ - высота образца после испытания, $b-$ средняя глубина прокорродировавшего слоя, определяемая металлографическим методом. Точность определения высоты образца до и после коррозионных испытаний составляет $\pm 20 \mu \mathrm{m}$. Точность определения глубины прокорродировавшего слоя составляет $\pm 50 \mu \mathrm{m}$.

Электронно-микроскопические исследования показывают, что в структуре титанового сплава наблюдается два типа областей, отличающихся существенно различным размером зерна (рис. 1,a).

Обобщение результатов испытаний на горячую солевую коррозию показывает, что в структуре сплава ПТЗВ наблюдается два типа коррозионных дефектов (рис. 1). Более протяженные дефекты МКК первого типа наблюдаются преимущественно в областях структуры, средний размер зерна в которых (до 50-100 $\mu \mathrm{m}$ ) намного превышает средний размер зерна основной мелкозернистой матрицы (зона I на рис. $1, a)$. Их глубина может достигать $L_{c o r(1)} \sim 500-700 \mu \mathrm{m}$ (тип I, рис. $1, b, 2, a)$, объемная доля таких дефектов МКК не превышает 5\% (на рис. 2, $а$ дефекты МКК первого типа отмечены стрелками).

Более короткие дефекты МКК второго типа наблюдаются в мелкозернистых (зона II) областях структуры титанового сплава (тип II на рис. $1, b)$. Их ширина мала, а среднее расстояние между ними составляет $\sim 5-10 \mu \mathrm{m}$ (рис. $2, b$ ). Глубина дефектов данного типа не превышает, как правило, $L_{c o r(2)} \sim 100-150 \mu \mathrm{m}$. Отметим также, что зачастую область материала с дефектами МКК второго типа „ограничена“ дефектами МКК первого типа (рис. 2,a).

Электронно-микроскопические исследования структуры свидетельствуют о том, что внутри мелких зерен $\alpha$-титана (зона II на рис. $1, a$ ) присутствуют хаотически расположенные решеточные дислокации. Часть дислокаций образует малоугловые границы. Рентгеноструктурными и электронно-микроскопическими исследованиями наличия $\beta$-фазы не выявлено. Параметры решетки, определенные методом рентгеноструктурного анализа, составляют $a=2.941 \AA, c=4.678 \AA$. Полученные значения соответствуют параметрам решетки $\alpha$-титана.

Энергодисперсионный анализ показывает наличие в структуре сплава ПТЗВ двух типов границ зерен. Первый тип - это границы зерен, которые мы назвали „чистыми“. Таких границ зерен абсолютное

Письма в ЖТФ, 2016, том 42, вып. 24 

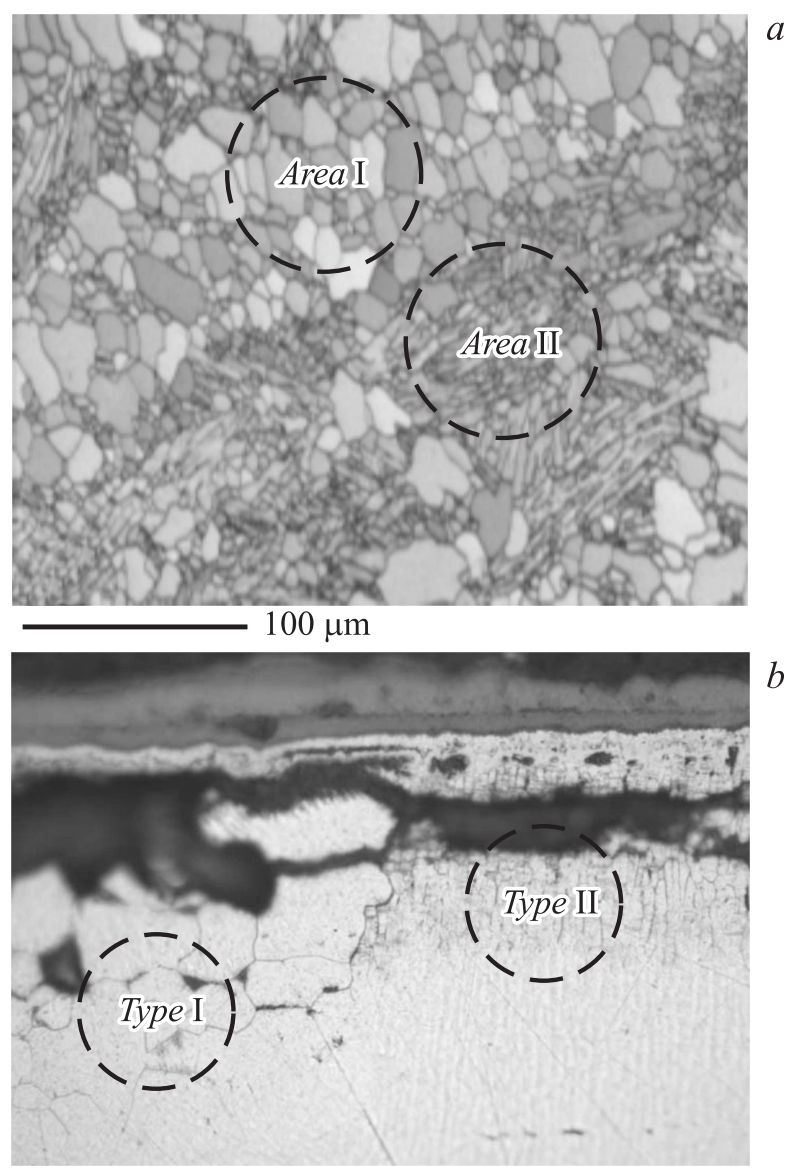

Рис. 1. Микроструктура сплава ПТЗВ $(a)$ и различные участки поверхности образцов после испытаний на горячую солевую МКК сплава ПТЗВ $(b)$.

большинство. Средняя локальная концентрация алюминия в таких границах зерен составляет $3.8 \pm 0.9 \mathrm{wt} \%$ (здесь и далее указана величина стандартного квадратичного отклонения), а средняя локальная концентрация ванадия $-1.9 \pm 0.2 \mathrm{wt} \%$, что мало отличается от концентрации этих элементов в объеме материала: средняя локальная концентрация

Письма в ЖТФ, 2016, том 42, вып. 24 

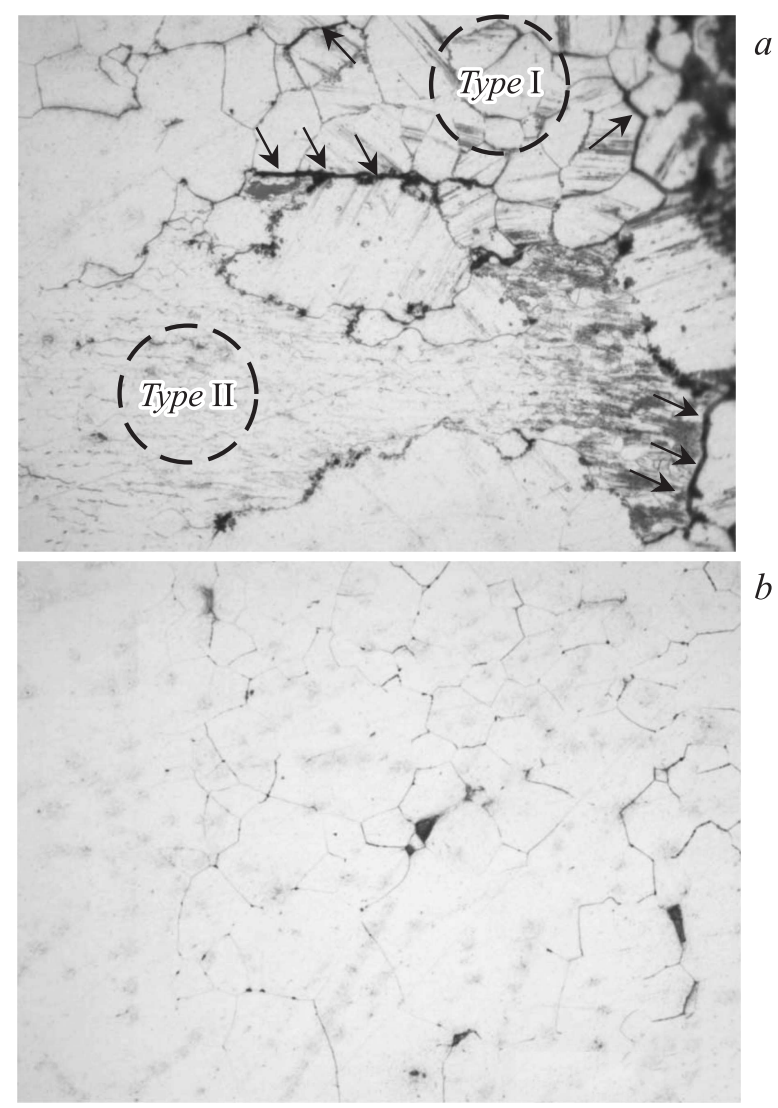

$50 \mu \mathrm{m}$

Рис. 2. Различные типы дефектов МКК в титановом сплаве ПТЗВ после испытаний на горячую солевую МКК: $a-$ характерный вид дефектов МКК первого типа (дефекты отмечены стрелочками), $b$ - характерный вид дефектов МКК второго типа.

алюминия в зернах составляет $3.6 \pm 0.9 \mathrm{wt} \%$, локальная концентрация ванадия $\sim 1.4 \pm 0.2 \mathrm{wt} \%$.

Второй тип границ - это границы зерен, локальная концентрация ванадия в которых может достигать $10 \mathrm{wt} \%$ (рис. 3,a). Встречаются 
также единичные границы, локальная концентрация ванадия в которых достигает 16-18 wt\%, а концентрация алюминия - менее $1 \mathrm{wt} \%$ (рис. $3, b)$. Средняя величина концентрации алюминия в кристаллической решетке вблизи таких границ составляет $\sim 4 \mathrm{wt} \%$, а концентрация ванадия - $1.6 \mathrm{wt} \%$. Отметим, что число таких границ невелико (менее 5\%, точная оценка их объемной доли затруднена из-за локальности используемого метода) и близко к объемной доле дефектов МКК первого типа, имеющих большую, по сравнению с дефектами второго типа, глубину.

Следует подчеркнуть, что обогащенные ванадием границы зерен наблюдаются на участках структуры титанового сплава, средний размер зерна которых существенно превышает средний размер мелкозернистой матрицы. Эти участки, по-видимому, возникли в процессе первичной рекристаллизации, при которой часто возникает неоднородное распределение зерен по размерам [14]. При первичной рекристаллизации миграция границ зерен может приводить к „заметанию“ мигрирующими границами зерен дефектов - атомов примесей и легирующих элементов, распределенных в кристаллической решетке, и возникновению границ зерен, обогащенных легирующими элементами. В данном случае миграция границ зерен привела к их обогащению ванадием, коэффициент распределения которого в титане составляет $K_{c}=0.8$ [15]. (Значения $K_{c}<1$ свидетельствуют о том, что примеси стремятся сегрегировать на границах зерен [16]).

Перейдем к обсуждению полученных экспериментальных результатов. В соответствии с теорией электрохимической коррозии [17], склонность сплавов к МКК определяется мощностью микрогальванических пар „граница зерна - кристаллическая решетка“. Здесь важно отметить, что „мощность“ возникающих микрогальванических пар „граница зерна - кристаллическая решетка“ зависит не от абсолютной концентрации легирующих элементов в границе зерна, а от разницы концентраций $\Delta C$ легирующих элементов в границе зерна $\left(C_{b}\right)$ и в кристаллической решетке $\left(C_{v}\right)$ сплава. (Вопрос об установлении взаимосвязи разницы концентраций $\Delta C$ и разности потенциалов „граница зерна $\left(\varphi_{b}\right)$ - кристаллическая решетка $\left(\varphi_{v}\right)^{\text {“ }}, \Delta \varphi=\varphi_{b}-\varphi_{v}$, которая и выступает в качестве меры „мощности“ возникающих микрогальванических пар, выходит за рамки настоящей работы).

В сплаве ПТЗВ для большинства „чистых“ границ зерен разница концентраций между границами зерен и кристаллической решет-

Письма в ЖТФ, 2016, том 42, вып. 24 


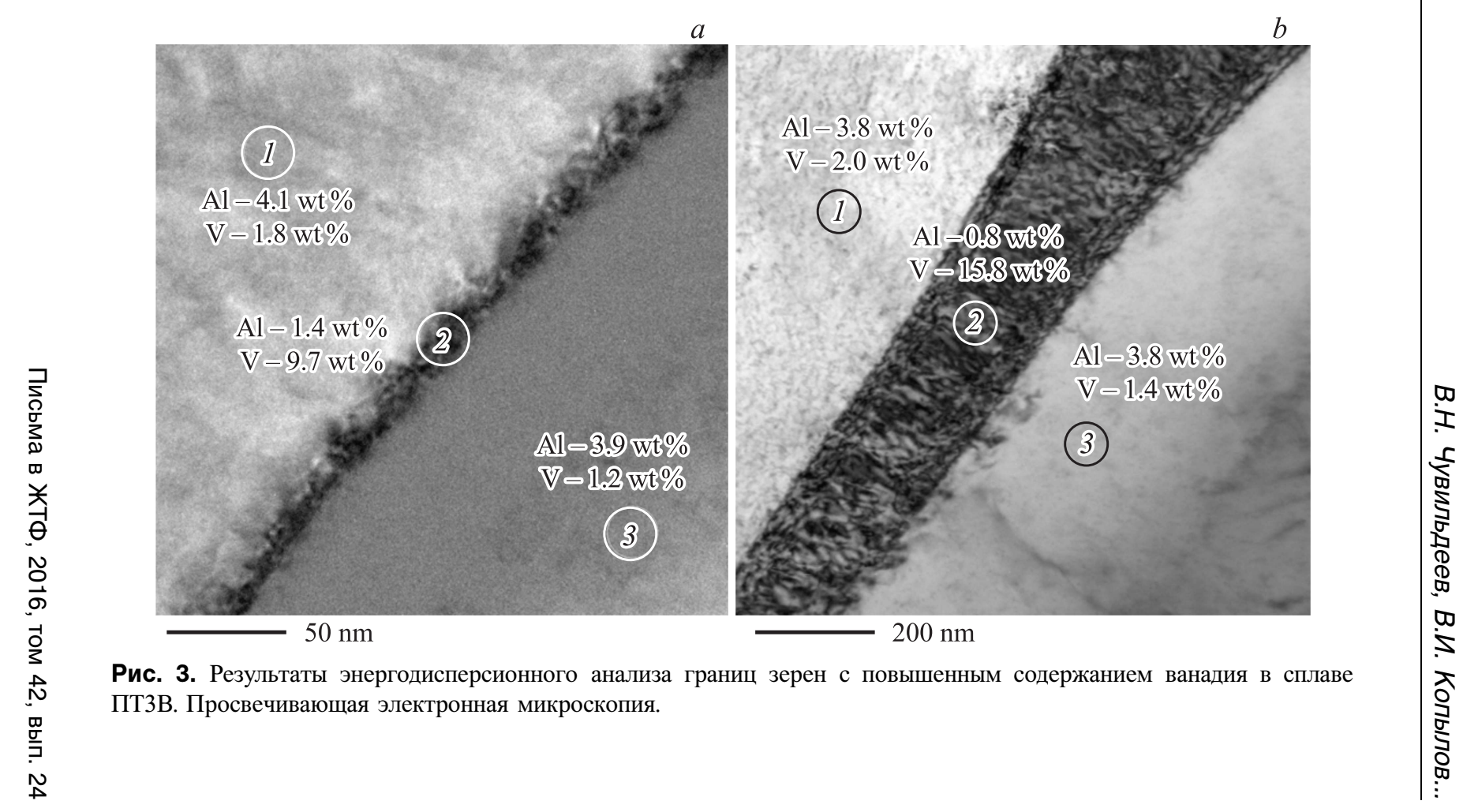


кой $\Delta C_{\mathrm{Al}}$ и $\Delta C_{\mathrm{V}}$ составляет $\sim 0.4$ at. \%, что незначительно превышает величину среднеквадратичного отклонения ( 0.2 at.\%). В случае же границ зерен, „обогащенных“ ванадием, разница концентраций $\Delta C_{\mathrm{Al}}$ и $\Delta C_{\mathrm{V}}$ составляет 5.6 и 12.9 at. \% соответственно. Это означает, что „обогащенные“ ванадием границы могут образовывать микрогальванические пары и стать „путями ускоренного распространения“ МКК в титановом сплаве ПТЗВ. (Вопрос о том, какая именно из величин $\Delta C_{\mathrm{Al}}$ или $\Delta C_{\mathrm{V}}$ - оказывает наибольшее влияние на склонность титанового сплава к МКК, выходит, в силу ограничения объема статьи, за рамки настоящей работы).

Таким образом, обобщая результаты проведенных исследований, следует отметить, что существенное влияние на склонность титановых сплавов к горячей солевой коррозии оказывает не только средний размер зерна, но и структурно-фазовое состояние границ зерен, в первую очередь - локальный химический состав границ зерен. Учет влияния данного фактора позволяет, на наш взгляд, объяснить описанный выше неоднозначный характер влияния среднего размера зерна на коррозионную стойкость титановых сплавов.

Работа выполнена при поддержке РНФ (грант № 16-13-00066).

\section{Список литературы}

[1] Коллинз E.В. Физическое металловедение титановых сплавов. М.: Металлургия, 1958. $224 \mathrm{c.}$

[2] Горынин И.В., Ушков С.С., Хесин Ю.Д. // Вопросы материаловедения. 1999. № 3 (20). С. 115-125.

[3] Ушков С.С., Кудрявщев А.С., Кирилин Э.Ф., Карасев Э.А. // Вопросы материаловедения. 1999. № 3 (20). С. 151-177.

[4] Томашов Н.Д. Титан и коррозионностойкие сплавы на его основе. М.: Металлургия, 1985. $80 \mathrm{c}$.

[5] Ralston K.D., Birbilis N. // Corrosion. 2010. V. 66. Iss. 7. P. $0750051-07500513$.

[6] Курзина И.А., Лямина Г.В., Фирхова Е.Б. и др. // Известия вузов. Физика. 2012. T. 55. № 5/2. С. 175-184.

[7] Чувильдеев В.Н., Копылов В.И., Бахметьев А.М. и др. // Доклады Академии наук. 2012. T. 442. № 3. С. 329-331.

[8] Kim H.S., Yoo S.J., Ahn J.W. et al. // Mater. Sci. Eng. A. 2011. V. 528. Iss. 29-30. P. 8479-8485.

Письма в ЖТФ, 2016, том 42, вып. 24 
[9] Balyanov A., Kutnyakova J., Amirkhanova N.A. et al. // Scripta Materialia. 2004. V. 51. Iss. 3. P. 225-229.

[10] Kim H.S., Kim W.J. // Corrosion Sci. 2014. V. 89. P. 331-337.

[11] Nie M., Wang C.T., Qu M. et al. // J. Mater. Sci. 2014. V. 49. Iss. 7. P. 2824-2831.

[12] Hoseini M., Shahryari A., Omanovic S., Szpunar J.A. // Corrosion Sci. 2009. V. 51. P. 3064-3067.

[13] Амирханова Н.А., Валиев Р.З., Черняева Е.Ю. и др. // Металлы. 2010. № 3. C. $108-110$.

[14] Горелик С.С., Добаткин С.В., Капуткина Л.М. Рекристаллизация металлов и сплавов. М.: МИСиС, 2005. $432 \mathrm{c.}$

[15] Кристаллизация из расплавов: Справочник / Под ред. К. Хайма, Э. Бурига. М.: Металлургия, 1989. $160 \mathrm{c.}$

[16] Чувильдеев B.Н., Смирнова E.C. // Физика металлов и металловедение. 2001. T. 92. № 2. C. 14-20.

[17] Томашов Н.Д. Теория коррозии и защиты металлов. М.: Изд-во АН СССР, 1960. $591 \mathrm{c}$. 